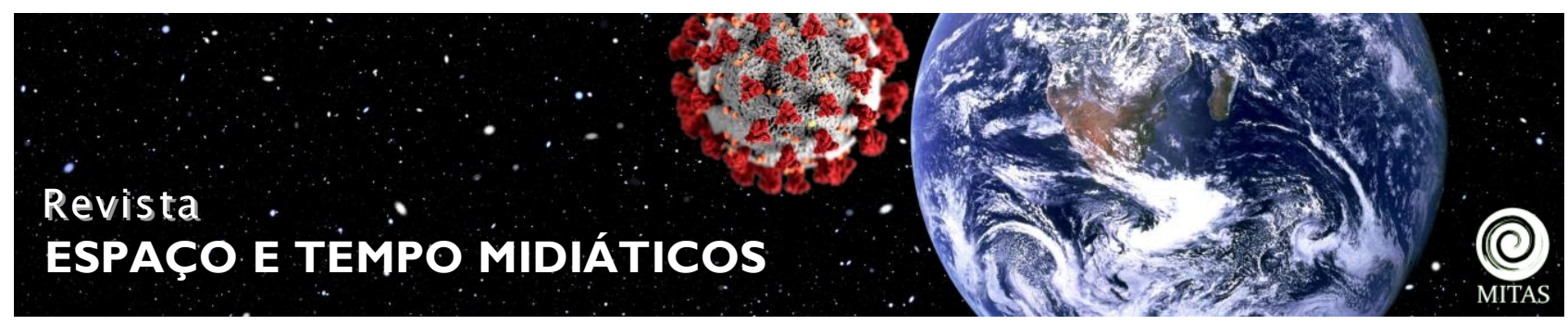

A pandemia da Covid-19 e o papel dos templos religiosos na disseminação do coronavírus: um estudo de caso na fronteira Brasil-Bolívia

Elisa Pinheiro de Freitas ${ }^{1}$, Claudia Araújo de Lima ${ }^{1}$, Gylize de Carvalho Ojeda ${ }^{1}$ e Jakline Franco Rodrigues ${ }^{1}$

${ }^{1}$ Universidade Federal de Mato Grosso do Sul (UFMS), Campus do Pantanal (CPAN), MS - Brasil

\begin{abstract}
Resumo
Com a atual pandemia da Covid-19, decretada pela Organização Mundial de Saúde (OMS) devido ao novo Sars-Cov-2, causador da Síndrome Respiratória Aguda Grave (SRAG) que em muitos casos é letal, o mundo atual tem sido impactado, uma vez que a globalização facilitou a circulação de pessoas e mercadorias. E esse ambiente transformou-se num facilitador para a rápida disseminação do novo coronavírus. A transmissão do Sars-Cov-2 ocorre principalmente: a) através de uma pessoa contaminada que, ao falar, tossir ou espirrar, emite gotículas que podem conter o coronavírus e infectar pessoas que estejam próximas fisicamente; b) contato comunitário; e c) contato com superfícies e/ou objetos contaminados. Por essa razão, as autoridades sanitárias da própria OMS, bem como dos distintos países, passaram a impedir aglomerações de pessoas, sobretudo em ambientes fechados cuja circulação de ar é limitada. No Brasil, governadores e prefeitos incumbiram-se de implementar as medidas para a contenção do novo coronavírus. Tomando por base o levantamento de informações em diferentes bancos de dados (DataSUS, IBGE, etc.), Boletim Coronavírus-MS (estadual), Boletim Covid-19 (Corumbá, municipal), análise dos decretos municipais e pesquisas científicas, o presente artigo aborda como a flexibilização do funcionamento dos templos religiosos pode ter concorrido para a rápida disseminação do Sars-Cov-2 no município de Corumbá-MS, localizado na região fronteiriça entre Brasil e Bolívia.
\end{abstract}

Palavras-chave: Pandemia da Covid-19; Sars-Cov-2; SRAG; Templos Religiosos; Fronteira Brasil-Bolívia.

\title{
Resumen
}

Con la actual pandemia de Covid-19, decretada por la Organización Mundial de la Salud (OMS) debido al nuevo Sars-Cov2, que provoca el Síndrome Respiratorio Agudo Severo (SARS), que en muchos casos es letal, el mundo en su conjunto ha sido afectados, desde que la globalización puso en marcha la amplia circulación de personas, bienes, etc., y ese entorno se ha convertido en un facilitador para la rápida propagación de este nuevo coronavirus. La transmisión de Sars-Cov-2 se produce principalmente: a) a través de una persona infectada que, al hablar, toser o estornudar, emite gotitas que pueden contener el coronavirus e infectar a personas cercanas físicamente; b) contacto con la comunidade; y c) contacto con superficies u objetos contaminados. Por ello, las autoridades sanitarias de la propia OMS, así como de los diferentes países, comenzaron a prevenir aglomeraciones de personas, especialmente en entornos con escasa circulación de aire. En Brasil, gobernadores y alcaldes se han comprometido a implementar medidas para contener el nuevo coronavirus. Con base en el relevamiento de información en diferentes bases de datos (DataSUS, IBGE, etc.), Boletín Coronavirus-MS (estado), Boletín Covid-19 (Corumbá, municipal), análisis de decretos municipales y artículos científicos, este artículo aborda cómo la flexibilidad en el funcionamiento de los templos religiosos puede haber contribuido a la rápida propagación de Sars-Cov-2 en el condado de Corumbá-MS, ubicado en la frontera Brasil-Bolivia.

Keywords: Pandemia de Covid-19; SARS-CoV-2; SARS; Templos religiosos; Frontera Brasil-Bolívia. 


\section{A PANDEMIA DA COVID-19E O PAPEL DOS TEMPLOS RELIGIOSOS NA DISSEMINAÇÃO DO CORONAVÍRUS: UM ESTUDO DE CASO NA FRONTEIRA BRASIL-BOLÍVIA}

\section{Introdução}

Com a atual pandemia da Covid-19, decretada em 11 de março de 2020, pela Organização Mundial de Saúde (OMS), devido a proliferação do novo Sars-Cov-2, também denominado de coronavírus, o mundo foi impactado, apesar das diferentes respostas que cada país tem dado a essa emergência internacional de saúde pública. O fato é que a globalização colocou em marcha a ampla circulação de pessoas, mercadorias, etc., e esse ambiente transformou-se num facilitador para a rápida disseminação desse novo coronavírus (De Lima Bezerra et al., 2020; Estellita et al., 2020; Lana et al., 2020; Oliveira et al., 2020; Souza e Ferreira Júnior, 2020; Silva et al., 2020; Tzanno-Martins, 2020).

A transmissão do Sars-Cov-2 ocorre principalmente: a) através de uma pessoa contaminada que, ao falar, tossir ou espirrar, emite gotículas e/ou catarro que podem conter o coronavírus e infectar pessoas que estejam próximas fisicamente; b) contato comunitário; e c) contato com superfícies e/ou objetos contaminados (De Lima Bezerra et al., 2020; Garcia, 2020; Lana et al., 2020; Pereira, Sá e Freitas, 2020; Silva et al., 2020; Tzanno-Martins, 2020).

Por essa razão, as autoridades sanitárias da própria OMS, bem como dos distintos países, passaram a impedir aglomerações de pessoas, sobretudo em ambientes fechados cuja circulação de ar é limitada, como as salas de aula, de cinema, de teatro, de templos religiosos, etc. Estudos apontam que o Sars-Cov-2 pode sobreviver no ar e, assim, infectar pessoas (Lednicky, John A. et al., 2020; Silva et al., 2020).

No fim de dezembro de 2019, o governo chinês comunicou às autoridades da OMS sobre a existência do novo vírus. E, no início de 2020, os casos de Covid-19 foram emergindo também na Europa e propagando-se muito rapidamente por todas as partes povoadas do mundo. As medidas de isolamento e de distanciamento social, com a implementação de quarentenas, foram tomadas por diferentes países, a começar pela China, que estabeleceu controle rigoroso para circulação de pessoas, isolando, a princípio, a cidade de Wuhan, onde se identificou a presença do patógeno e, em seguida, toda a província de Hubei, cuja população absoluta corresponde a 58,5 milhões (De Lima Bezerra et al., 2020; Estellita et al., 2020; Garcia, 2020; Lana et al., 2020; Lopes, 2020; Oliveira et al., 2020; Tzanno-Martins, 2020).

Essa estratégia de isolamento e de distanciamento social associada a quarentenas rígidas também foram adotadas por diversos países europeus, uma vez que essas Intervenções Não Farmacológicas (INF) eram as que estavam disponíveis para assegurar a vida das populações diante de um vírus do gênero Betacoronavírus, que provoca, em parte dos seres humanos, a Síndrome Respiratória Aguda Grave (SRAG), daí a designação de Sars-Cov-2. Esta doença tende a ser mais letal para aqueles que apresentam comorbidades (diabete, obesidade, hipertensão, etc.) e para as pessoas de faixa etária acima de 60 anos (Estellita et al., 2020; Garcia, 2020; Lana et al., 2020; Pereira, Sá e Freitas, 2020; Tzanno-Martins, 2020).

O período de incubação da Covid-19 é em torno de sete dias, sendo que os principais sintomas relatados incluem, segundo Tzanno-Martins (2020, p. 2):

Em ordem decrescente, os sintomas mais comuns são febre,
fadiga, tosse seca, anorexia, mialgia e dispneia. A febre pode
ser bem baixa (<38 graus) em $20 \%$ dos casos. Após o iní-
cio dos sintomas, a dispneia pode permanecer e a SARS se
desenvolve em média 8 dias após o início, necessitando mui-
tas vezes de ventilação mecânica prolongada (em média, 20
dias). O leucograma em geral é normal e a linfopenia, fre-
quente, nos casos mais graves.

Também os diferentes chefes de estados dos primeiros países atingidos pela pandemia estabeleceram o fechamento das fronteiras para o trânsito de pessoas, permitindo apenas o fluxo de mercadorias com vistas a garantir o abastecimento dos produtos essenciais. Com os primeiros casos de Covid-19 na América do Sul, igualmente se verificou o fechamento das fronteiras por vias terrestres, aéreas e marítimas para conter a rápida disseminação do coronavírus nesta região do globo (Cazarré, 2020).

Dessa maneira, como aponta Oliveira (2020), observar o comportamento de outros países no enfrentamento da Covid-19 fez-se necessário para as demais nações prevenirem-se, pois a propagação do vírus poderia ocorrer na mesma velocidade, em maior ou menor grau de contágios:

Assim, o que acontece em um país pode trazer impacto a outros povos e/ou nações, tal como a proliferação de vírus e doenças, devido ao grande fluxo de pessoas viajando pelo mundo afora, seja em turismo ou negócios. Deste modo, vive-se nesses tempos globalizados ambientes propícios para proliferação de vírus/doenças e surgimento de pandemias (Oliveira, 2020, p. 259)

Desta feita, o Brasil pode observar como o novo SarsCov-2 comportava-se e os efeitos que provocava nos sistemas de saúde dos países do hemisfério norte. O Ministério da Saúde, chefiado pelo ministro e médico Luiz Henrique Mandetta, veiculou as medidas e as recomendações para conter a disseminação da doença em território brasileiro. 

ESTUDO DE CASO NA FRONTEIRA BRASIL-BOLÍVIA

No dia 26 de fevereiro de 2020, notificou-se, oficialmente, o primeiro caso de Covid-19 no estado de São Paulo, que se tornou, no país, o epicentro da doença (Lana et al., 2020; Oliveira et al., 2020; Tzanno-Martins, 2020).

Contudo, estudos liderados por pesquisadores da Fundação Oswaldo Cruz (Fiocruz) confirmaram que já havia transmissão comunitária do Sars-Cov-2 pelo país em fevereiro de 2020 (Delatorre et al., 2020). Ainda estudos identificaram a presença do Sars-Cov-2 em amostras de águas residuais (esgoto) em Santa Catarina e sinalizaram que, possivelmente, o patógeno já estivesse no Brasil desde novembro de 2019 (Fongaro et al., 2020). E, recentemente, um estudo publicado pelo Centro de Controle e Prevenção de Doenças (CDC) dos EUA demonstrou que pesquisadores identificaram ao menos 39 pessoas que teriam desenvolvido anticorpos para o novo coronavírus anterior ao alerta dos chineses às autoridades da OMS para o novo vírus. Tal fato coloca em dúvida a origem geográfica da pandemia.

$\mathrm{O}$ fato é que as medidas de contenção ao novo coronavírus passaram a ser implementadas a partir de março de 2020 por governadores e prefeitos que, por meio de decretos, regularam o funcionamento de estabelecimentos comerciais, industriais e de serviços, da realização de eventos e de quaisquer tipos de reunião que promovessem aglomerações (Silva e Silveira, 2020). Estabelecimentos de ensino, teatros, museus, etc. foram encerrados e só retornariam ao funcionamento quando as autoridades sanitárias estaduais e municipais estivessem seguros quanto ao controle da Covid-19 e que a rede hospitalar do Sistema Único de Saúde (SUS) não tivesse ocupação de leitos clínicos e de UTIs acima de $80 \%$. Dito isto, entre as instituições afetadas com a implementação de decretos restritivos às aglomerações de qualquer natureza, estão as organizações religiosas e, por conseguinte, o funcionamento dos templos religiosos (Silva e Silveira, 2020).

Tomando por base o levantamento de informação em diferentes bancos de dados (DataSUS, IBGE, etc.), Boletim Coronavírus-MS (estadual), Boletim Covid-19 (Corumbá -municipal), análise dos decretos municipais e de artigos científicos, o presente artigo buscou demonstrar como a flexibilização do funcionamento dos templos religiosos pode ter concorrido para a rápida disseminação do Sars-Cov-2 no município de Corumbá-MS, localizado na fronteira BrasilBolívia. Foi observado o aumento significativo do número de casos entre os meses de maio e julho, período este que coincidiu com a flexibilização no funcionamento dos templos religiosos.

Este artigo ainda se subdivide em mais quatro partes, sendo que na próxima discorre-se sobre o percurso teórico- metodológico para a sistematização dos dados; a terceira traz a discussão sobre a contaminação de fiéis ocorrida em templos religiosos em algumas partes do mundo; a quarta parte trata dos decretos municipais e os impactos do funcionamento dos templos religiosos no crescimento de casos de Covid-19 e, nas considerações finais, sintetizam-se as principais questões abordadas ao longo deste artigo.

\section{Percurso teórico-metodológico para o desenvolvimento da pesquisa}

O desenvolvimento da pesquisa deu-se sob o ponto de vista de natureza aplicada sobre o funcionamento dos templos religiosos e como estes impactaram a pandemia da Covid-19 em Corumbá-MS. A cidade de Corumbá está localizada na região Centro-Oeste do estado de Mato Grosso do Sul, fazendo fronteira com a Bolívia e Paraguai. Conforme o Boletim Covid-19 de Corumbá e de Ladário (MSBRA) e o Boletim Covid-19 do Departamento de Santa Cruz (BOL), até a data do dia 15 de setembro de 2020, essa região fronteiriça somava, em números absolutos, $4.401 \mathrm{ca}-$ sos acumulados de Covid-19, conforme os dados representados na Figura 1 abaixo.

\section{Figura 1}

Casos de Covid-19 na região de fronteira Brasil-Bolívia

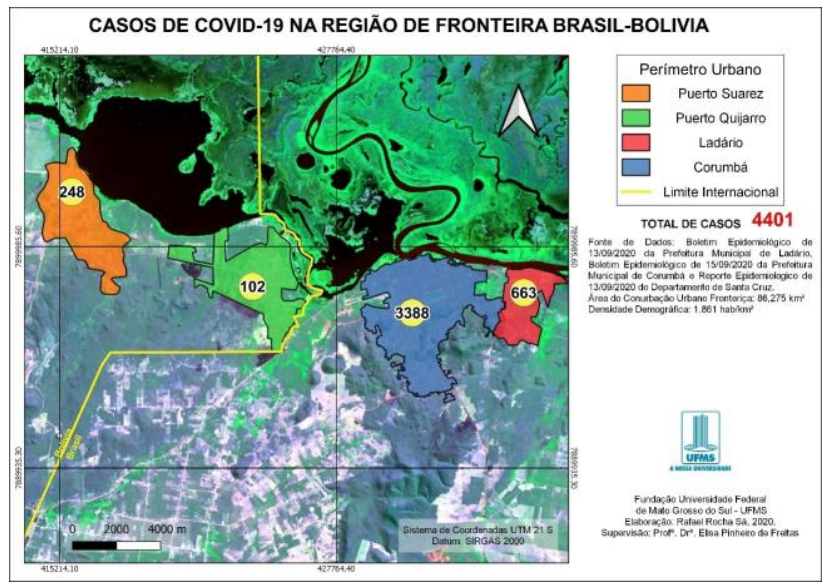

Boletim Epidemiológico Covid-19 - Corumbá-MS.

O estudo analisou como os decretos publicados pelo poder executivo do município de Corumbá-MS implicaram (ou não) a contenção da Covid-19. Como foi preconizado pela OMS, era de suma importância que os chefes de estados com o suporte das autoridades sanitárias deveriam cessar eventos religiosos, shows, festas etc. tendo em vista que 

ESTUDO DE CASO NA FRONTEIRA BRASIL-BOLÍVIA

tais atividades eram espalhadoras de coronavírus (Silva e Silveira, 2020).

De posse da informação que templos religiosos, salas de aula, casas show, festas etc. poderiam se epicentros de disseminação de Sars-Cov-2, caso fossem mantidos em funcionamento, identificou-se, pelo georreferenciamento, o total de 79 templos religiosos em Corumbá que possuem maior representatividade no município (igrejas católicas, igrejas pentecostais e neopentecostais) e que estão localizados, conforme a Figura 2, por bairros:

Enquanto Corumbá possui um total de 79 templos religiosos, o mesmo município dispõe o total de 68 estabelecimentos de ensino (Básico e Médio, da rede privada e da rede pública), com mais de 20 mil alunos matriculados, de acordo com os dados do Instituto Brasileiro de Geografia e Estatística (IBGE). E desde o Decreto Municipal n. ${ }^{\circ}$ 2.270, de 23 de março de 2020, as aulas presenciais foram suspensas para impedir as aglomerações e, consequentemente, a disseminação do Sars-Cov-2. Ocorre que o Decreto Municipal n. ${ }^{\circ} 2.289$, de 20 de abril de 2020, flexibilizou o funcionamento dos templos religiosos.

\section{Figura 2}

Quantitativo dos templos e centros religiosos em Corumbá-MS

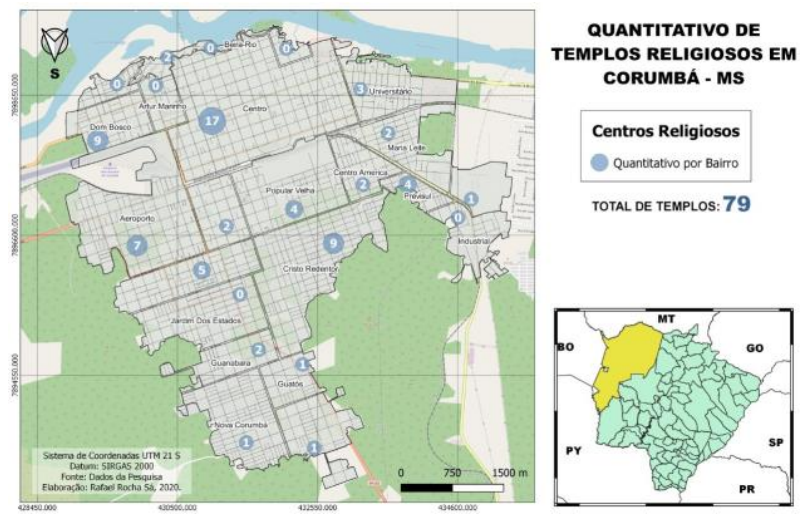

IBGE Cidades-Corumbá (MS), 2020.

Assim, buscou-se estabelecer uma correlação entre a quantidade de casos acumulados de Covid-19, por bairros, e a quantidade de templos religiosos existentes, de modo a demonstrar que as flexibilizações para a realização de cultos e de missas presenciais, mesmo com número reduzidos de pessoas, podem ter potencializado os templos religiosos a tornarem-se epicentros de disseminação do Sars-Cov-2.
Para tanto, os dados do Boletim Covid-19 publicado pela Secretaria Municipal de Saúde do município de Corumbá serviu de fonte para se realizar essa correlação e essa análise espacial.

A coleta de dados a partir dos Boletins Epidemiológicos foi realizada entre os meses de junho e de agosto de 2020 e, ainda, procurou-se aplicar, para esse estudo, a forma descritiva que, como aponta Gil (2008, p. 18), "as pesquisas deste tipo têm como objetivo primordial a descrição das características de determinada população ou fenômeno ou o estabelecimento de relações entre variáveis". Quanto aos procedimentos técnicos, trata-se de uma pesquisa bibliográfica e, segundo Gil (2002 p. 44), é desenvolvida a partir de estudos anteriores, constituídos principalmente de livros e de artigos científicos (Gil, 2002, p. 50).

Do ponto de vista da abordagem do problema, o estudo é classificado como qualitativo e quantitativo. Cabe destacar que alguns autores entendem a pesquisa qualitativa como uma "expressão genérica". Isto significa, por um lado, que ela compreende atividades de investigação que podem ser denominadas específicas e, por outro, que todas elas podem ser caracterizadas por traços comuns. Esta é uma ideia fundamental, que pode ajudar a ter uma visão mais clara do que pode chegar a realizar um pesquisador que tem por objetivo atingir uma interpretação da realidade do ângulo qualitativo (Triviños, 1987, p. 120).

Visto que muitos fiéis possuem o entendimento dos templos religiosos como território sagrado, nos quais podem estabelecer interações com os outros e com a divindade na qual creem (Saquet, 2018) e, embora o encerramento dos templos religiosos fosse uma medida de difícil execução, por ter de afastar os fiéis de seus templos, era necessária para conter a rápida propagação do coronavírus e, consequentemente, evitar os óbitos por Covid-19 (Silva e Silveira, 2020; Py et. al., 2020).

\section{Templos religiosos e a contaminação de fiéis pelo novo coronavírus}

A pandemia da Covid-19, pela sua gravidade, tomou conta dos noticiários no mundo inteiro, o que possibilitou aos autores deste artigo terem um panorama global de como as diferentes organizações religiosas afetaram e foram afetadas pela pandemia do novo coronavírus. Salientase que há informações de que templos religiosos cujos líderes não suspenderam as manifestações presenciais dos fiéis serviram como potenciais meios de transmissão da Covid19. Como destacou Fernandes (2020), uma equipe norteamericana responsável pelo Centro de Controle e Prevenção de Doenças (CDC) conseguiu identificar 35 casos de 

ESTUDO DE CASO NA FRONTEIRA BRASIL-BOLÍVIA

Covid-19 num grupo de 92 fiéis de uma igreja no estado de Arkansas (EUA).

Ainda no estado da Virgínia Ocidental (EUA), suspeita-se de que a flexibilização e o retorno da participação presencial de fiéis nos cultos religiosos tenham contribuído para a explosão de casos de Covid-19, conforme noticiou o IG notícias. Na Coreia do Sul também há registro de novos contágios pelo vírus conforme noticiado pelo jornal Estado de Minas, que mostra que o culto presencial na Igreja de Jesus Shincheonji ocasionou o contágio de um terço dos fiéis pelo novo vírus.

No Brasil, de acordo com a revista Exame, os casos da Covid-19 dobraram em Santa Catarina, por exemplo, logo após a reabertura de shoppings e igrejas (Cerioni e Garret Júnior, 2020). O portal de notícias da revista supracitada mostra que, em apenas dez dias de flexibilização, o estado de Santa Catarina teve o dobro de números de casos positivos para a Covid-19.

Mesmo diante do crescente número de casos de Covid19, o presidente brasileiro, por meio do Decreto Presiden-

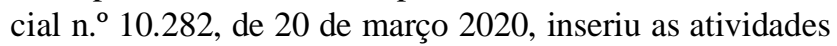
religiosas como sendo serviços públicos essenciais:

\footnotetext{
Art. 3. ${ }^{\circ}$ As medidas previstas na Lei n. ${ }^{\circ} 13.979$, de 6 de fevereiro de 2020, deverão resguardar o exercício e o funcionamento dos serviços públicos e atividades essenciais a que se refere o $\$ 1$. $^{\circ}$.

$\S 1$. $^{\circ}$ São serviços públicos e atividades essenciais aqueles indispensáveis ao atendimento das necessidades inadiáveis da comunidade, assim considerados aqueles que, se não atendidos, colocam em perigo a sobrevivência, a saúde ou a segurança da população, tais como: [...] XXXIX - atividades religiosas de qualquer natureza, obedecidas as determinações do Ministério da Saúde. (grifo nosso)
}

Sob esse prisma, podemos observar uma contradição quanto ao decreto presidencial que permitiu o funcionamento dos templos religiosos e dificultou a contenção da Covid-19 por parte dos poderes executivos estaduais e municipais, haja vista que governadores e prefeitos adotaram as recomendações da OMS e buscaram impedir as reuniões ou aglomerações de qualquer natureza (Silva e Silveira, 2020; Py et. al. 2020). Já o governo federal adotou uma postura despreocupada, negligenciando o perigo que a doença poderia trazer a milhares de pessoas. Da data do Decreto n. ${ }^{\circ} 10.282$, de 20 de março 2020 , até o dia 28 de dezembro de 2020, o Brasil acumulou mais de 7 milhões de pessoas infectadas pela Covid-19 e mais de 191 mil óbitos, sendo o terceiro país no mundo com mais casos e o segundo em óbitos absolutos provocados pelo novo coronavírus (Johns Hopkins University, 2020).
Conforme divulgou a imprensa brasileira, as medidas que causaram divergência entre as autoridades sanitárias e o teor do decreto presidencial do dia 20 de março de 2020 é a inclusão de igrejas e de templos na classificação de serviços essenciais. Esta inserção causou uma discussão até mesmo dentro das igrejas, haja vista que padres e pastores têm sido infectados, e vários deles perderam suas vidas. Nos últimos meses, mais de 400 padres e bispos brasileiros contraíram a Covid-19, e cerca de 21 faleceram em decorrência de complicações da doença (Barbosa, 2020). Conforme noticiado pela Agência Senado, em 3 de julho de 2020:

\footnotetext{
O presidente Jair Bolsonaro, porém, vetou a obrigatoriedade do uso da máscara de proteção individual em órgãos e entidades públicas e em estabelecimentos comerciais, industriais, templos religiosos, instituições de ensino e demais locais fechados em que haja reunião de pessoas. Ao justificar os vetos, o Planalto alega, entre outras razões, que a obrigatoriedade 'incorre em possível violação de domicílio'.
}

O uso das máscaras tornou-se obrigatório em todo o Brasil, tendo em vista que as autoridades da OMS, baseadas em estudos científicos, observaram que elas constituíam uma barreira física para evitar a disseminação ou a transmissão de alta carga viral (Garcia, 2020; Silva et al., 2020). Mas com o veto presidencial, o uso de máscaras no interior dos templos religiosos ou em instituições públicas deixou de ser obrigatório. O plenário do Supremo Tribunal Federal (STF), em abril de 2020, acolheu ações contra a Medida Provisória 926 de 2020 e decidiu que estados e municípios tinham autonomia para executar medidas sanitárias, epidemiológicas e administrativas relacionadas ao combate do novo coronavírus (Silva e Silveira, 2020; Py et. al., 2020; Strapazzon, 2020).

\section{Medidas de contenção do coronavírus num município fronteiriço}

Para contenção da transmissibilidade da Covid-19, o município de Corumbá-MS passou a adotar medidas seguindo orientações da OMS. O Decreto Municipal n. ${ }^{\circ}$ 2.269, de 21 março de 2020, estabeleceu o horário de funcionamento do comércio em geral e de prestação de serviços, de segunda-feira a sexta-feira, das $8 \mathrm{~h}$ às $16 \mathrm{~h}$ e, aos sábados, das $8 \mathrm{~h}$ às $14 \mathrm{~h}$, vedado seu funcionamento aos domingos. Foi estabelecido o toque de recolher diário das $20 \mathrm{~h}$ às $4 \mathrm{~h}$. Posteriormente, reafirmando o distanciamento social, o Decreto Municipal n. ${ }^{\circ} 2.270$, de 23 de março de 2020 , suspendeu os eventos de qualquer natureza que implicasse aglomeração de pessoas enquanto perdurarem as 


\section{A PANDEMIA DA COVID-19E O PAPEL DOS TEMPLOS RELIGIOSOS NA DISSEMINAÇÃO DO CORONAVÍRUS: UM ESTUDO DE CASO NA FRONTEIRA BRASIL-BOLÍVIA}

regras previstas pelos órgãos de saúde no combate à pandemia da Covid-19. Assim entraram nesta restrição os estabelecimentos privados comerciais já licenciados, inclusive as igrejas, que não poderiam realizar missas e cultos religiosos presenciais, academias de ginásticas e demais práticas esportivas, museus, bibliotecas e centros culturais.

Em abril de 2020, a cidade apresentou o primeiro caso de Covid-19. Contudo, é preciso salientar que é provável que o coronavírus já circulasse no município antes do primeiro caso notificado, pois a circulação de produtos e bens não foi interrompida porque foram classificadas como essenciais. Outra questão que deve ser levada em consideração é que o Brasil é o país que menos testa sua população; então há um gap entre os casos notificados e as subnotificações, até porque, inicialmente, o Ministério da Saúde orientou testar apenas os casos sintomáticos graves de SRAG (Garcia, 2020; Oliveira et al., 2020).

Em decorrência das discussões travada pela Frente Parlamentar Evangélica, no âmbito federal, em consonância com as diferentes lideranças religiosas e com o apoio Presidencial, os gestores estaduais e municipais foram pressionados a reverem os decretos que impediam o funcionamento dos templos religiosos (Silva e Silveira, 2020; Py et. al., 2020).

Desse modo, a 20 de abril de 2020 foi implementado o Decreto Municipal n. ${ }^{\circ}$ 2.289, que estabeleceu normas temporárias relacionadas às reuniões religiosas em igrejas, templos, centros espíritas e demais locais destinados as manifestações religiosas. A normatização orientou os seguintes procedimentos:

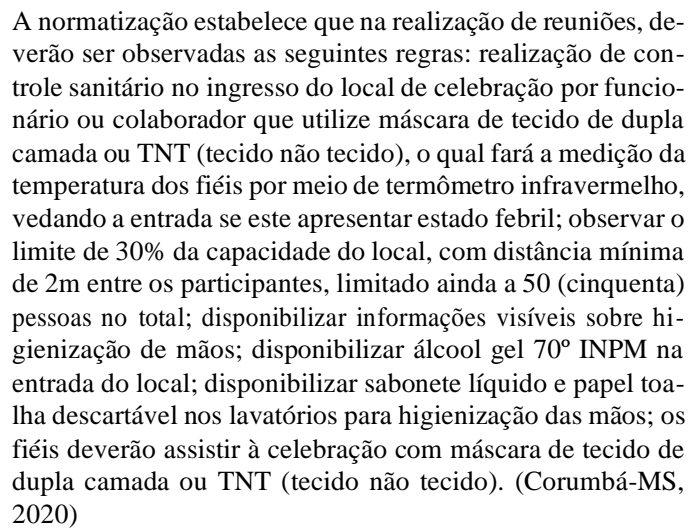

Entre a data do Decreto supracitado (20 de abril de 2020) até 16 de julho de 2020, Corumbá registrou 666 casos acumulados de Covid-19; encerrando o mês de julho com 1.020 casos, conforme a Figura 3, e com 39 óbitos, conforme pode ser conferido na Figura 4:

\section{Figura 3}

Casos acumulados de Covid-19 em Corumbá-MS até agosto de 2020

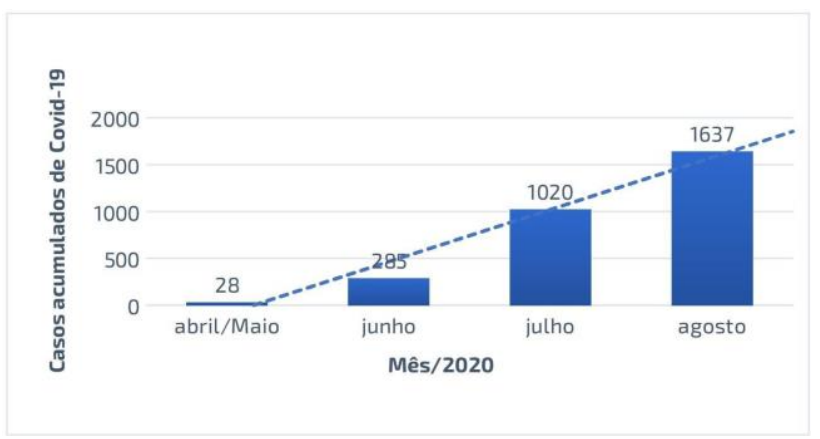

Boletim Epidemiológico Covid-19 - Corumbá-MS

Com o crescimento de número de casos confirmados de Covid-19 em Corumbá, em 16 de julho de 2020 foi implementado o Decreto Municipal n. ${ }^{\circ}$ 2.356, que, entre outras medidas, orientou os responsáveis por templos religiosos a anotarem o nome dos fiéis, telefone, endereço, etc. para facilitar o contato da equipe de vigilância epidemiológica em caso de contaminação.

\section{Figura 4}

Óbitos acumulados de Covid-19 em Corumbá até agosto de 2020

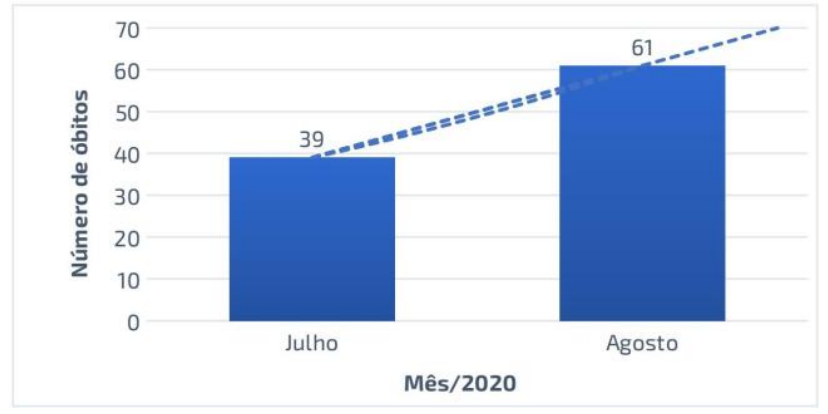

Boletim Epidemiológico Covid-19 - Corumbá-MS

Corumbá registrou, naquela data, conforme demonstra a Figura 5, 666 casos de Covid-19, um aumento de quase $600 \%$ em relação a 16 de junho de 2020, quando o município registrou 145 casos de Covid-19, de acordo com os dados obtidos pelo Boletim epidemiológico da Figura 6. 


\section{Figura 5}

Bairros com casos de Covid-19 em Corumbá até 16 de julho de 2020

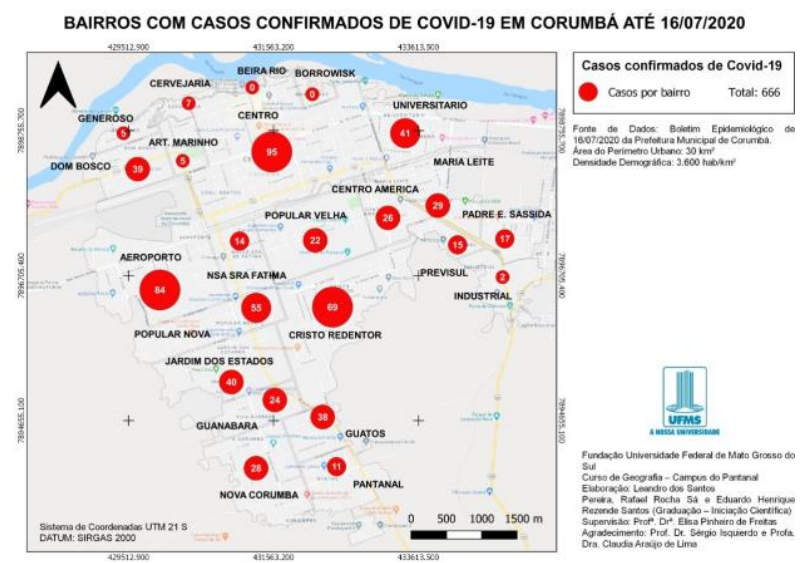

Boletim Epidemiológico Covid-19 - Corumbá-MS

\section{Figura 6}

Bairros com casos de Covid-19 em Corumbá até 16 de julho de 2020

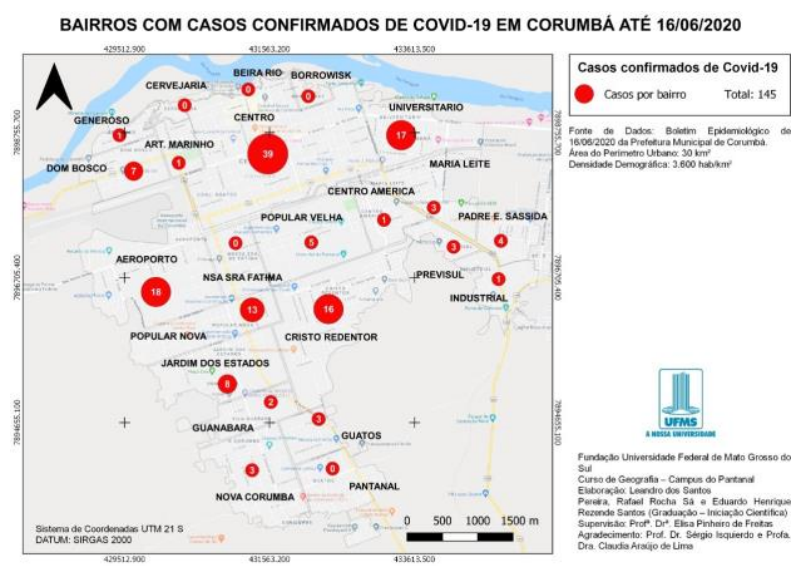

Boletim Epidemiológico Covid-19 - Corumbá-MS

Com esse crescimento num intervalo de 30 dias (entre 16 de junho e 16 de julho de 2020), em 30 de julho foi publicado novo Decreto Municipal n. ${ }^{\circ}$ 2.364/2020, que dispôs de um conjunto de medidas restritivas para frear a circulação do vírus na cidade. Ele alterou o horário de funcionamento dos prestadores de serviços, podendo os estabelecimentos comerciais ficarem abertos de segunda a sextafeira, no horário das $8 \mathrm{~h}$ às $16 \mathrm{~h}$ e, aos sábados, das $8 \mathrm{~h}$ às $14 \mathrm{~h}$, com fechamento aos domingos, exceto algumas categorias como: supermercados, farmácias, açougues, restaurantes, lanchonetes, clínicas médicas, clínicas odontológicas, laboratórios, clínicas veterinárias, sorveterias e padarias. Esse decreto, porém, não alterou o funcionamento dos templos religiosos.

Em 25 de agosto de 2020, conforme os dados da Figura 7, Corumbá já apresentava 2.329 casos de Covid-19 e, de acordo com os dados da Figura 8, 83 óbitos:

\section{Figura 7}

Bairros com casos de Covid-19 em Corumbá até 25 de agosto de 2020

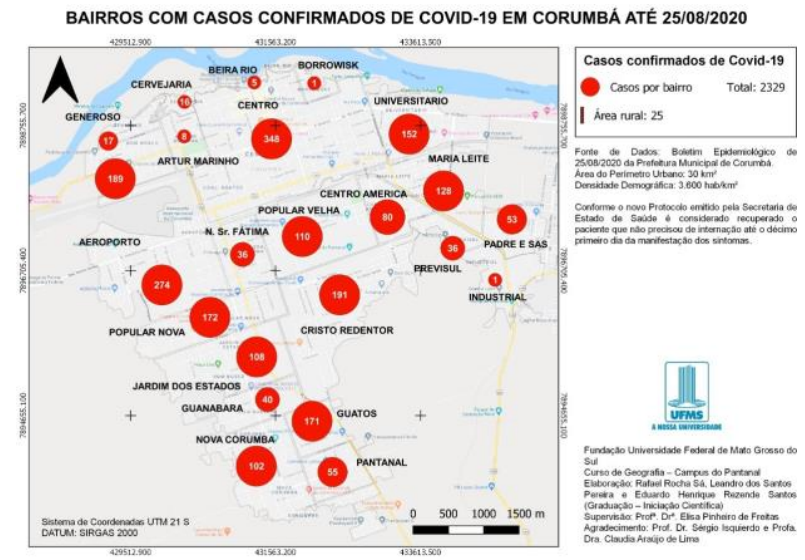

Boletim Epidemiológico Covid-19 - Corumbá-MS

Com 83 óbitos por Covid-19 e tendo uma taxa de mortalidade de 3,8, calculada a partir dos dados disponibilizados pelo Boletim Coronavírus, da Secretaria Estadual de Saúde de Mato Grosso do Sul, Corumbá é a quarta maior cidade do Estado, respondendo por $10 \%$ dos óbitos de MS, mas com apenas $4 \%$ da população absoluta. No dia 25 de agosto de 2020 foi publicado o Decreto Municipal n. ${ }^{\circ} 2.381$, que restringiu o funcionamento dos templos religiosos no município às quartas-feiras, aos sábados e domingos, com limitação de duas celebrações diárias. 


\section{Figura 8}

Bairros com óbitos por Covid-19 em Corumbá até 25 de agosto de 2020

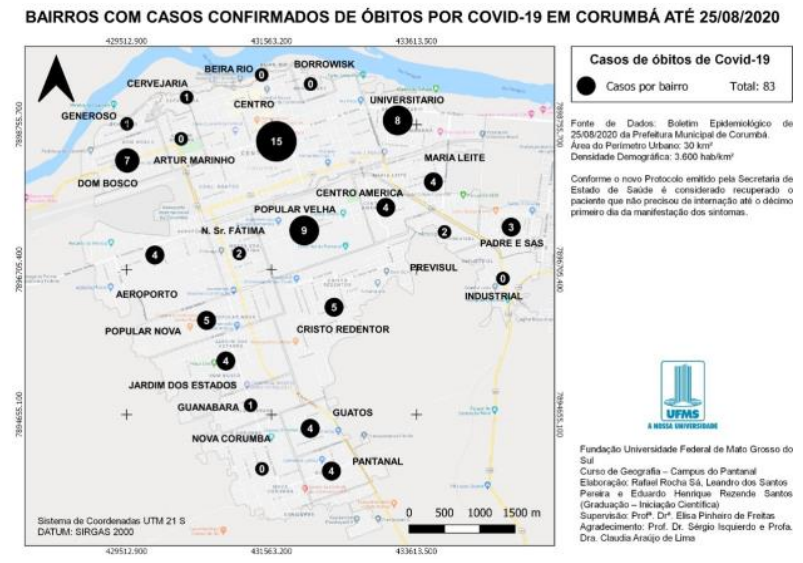

Boletim Epidemiológico Covid-19 - Corumbá-MS

Podemos observar que os decretos buscaram prevenir a propagação do vírus, estabelecendo normas que até certo ponto limitaram o fluxo de pessoas durante os eventos religiosos. Sendo bem restritivo no início, como o Decreto n. ${ }^{\circ} 2.268$, com o passar dos meses foram sendo flexibilizados, apesar do aumento dos casos diários. Ao que tudo indica, essas flexibilizações em relação às aglomerações em templos religiosos concorreram para o aumento de casos de infecção por coronavírus na cidade de Corumbá, o que pode explicar, em parte, a alta mortalidade da doença neste município.

Como já se mencionou neste artigo, ambientes fechados cuja circulação de ar é limitada, como salas de aulas, de cinema, de teatro, de templos religiosos, etc., propiciam a contaminação comunitária. Há que se considerar, conforme estudos, que $86 \%$ das contaminações são feitas por pessoas assintomáticas, portadoras do vírus (De Lima Bezerra et al., 2020). E durante a realização de cultos e de missas há momentos de cantos, etc., podendo haver grande emissão de gotículas contendo o vírus, e ele, como apontam estudos científicos, é capaz de sobreviver no ar (Garcia, 2020, p. 3).

De acordo com o Instituto Brasileiro de Geografia e Estatística (IBGE, 2010), Corumbá conta com uma grande diversidade de crenças religiosas: $64 \%$ da população é constituída por católicos, $25 \%$ são evangélicos, $5 \%$ não têm religião, $2 \%$ são espíritas e $1 \%$ professa o budismo e as religiões de matriz africana (candomblé, umbanda, etc.).

O município de Corumbá é composto por 23 bairros. São eles: Aeroporto, Arthur Marinho, Beira-Rio, Borrowiski, Centro, Centro-América, Cervejaria, Cristo Reden- tor, Dom Bosco, Generoso, Guarani, Guatós, Industrial, Jardim dos Estados, Maria Leite, Nossa Senhora de Fátima, Nova Corumbá, Padre Ernesto Sassida, Pantanal, Popular Nova, Popular Velha, Previsul e Universitário.

Tabela 1 sintetiza o conjunto de decretos que restringiu e flexibilizou o funcionamento dos templos religiosos em Corumbá: 


\section{Tabela 1}

Decretos Municipais sobre funcionamento dos serviços durante a pandemia de Covid-19. Fonte: Dos autores a partir do Diário Oficial de Corumbá-MS - 2020

\begin{tabular}{|c|c|c|}
\hline $\begin{array}{l}\text { Data do de- } \\
\text { creto }\end{array}$ & Número & Funcionamento dos Templos Religiosos \\
\hline $21 / 3 / 2020$ & $\begin{array}{l}\text { DECRETO } \\
\text { n. } 2.268\end{array}$ & $\begin{array}{l}\text { D E C R E T A: } \\
\text { Art. 1. }{ }^{\circ} \text { Fica reconhecida emergência no Município de Corumbá, para enfrenta- } \\
\text { mento da pandemia decorrente do coronavírus - Covid-19, de importância interna- } \\
\text { cional. } \\
\begin{array}{l}\text { Disponível em: } \quad \text { https://do.corumba.ms.gov.br/corumba/portal/visualizacoes/ } \\
\text { pdf/3638/\#/p:1/e:3638 }\end{array}\end{array}$ \\
\hline $23 / 3 / 2020$ & $\begin{array}{l}\text { DECRETO } \\
\text { n. } 2.270\end{array}$ & $\begin{array}{l}\text { D E C R E T A: Art. 1. }{ }^{\circ} \text { Fica instituído o Comitê Gestor de Crise - Pandemia } \\
\text { Covid-19, de caráter deliberativo, com as seguintes atribuições: } \\
\text { IV - disciplinar sobre fatos excepcionais que sejam referentes às medidas de en- } \\
\text { frentamento ao Covid-19, no âmbito do Poder Executivo, tais como: a) suspensão e } \\
\text { descontinuidade de serviços públicos; b) possibilidade de trabalho remoto de servi- } \\
\text { dores; c) funcionamento de órgãos e entidades da Administração Pública; d) outros } \\
\text { eventos que o comitê entenda como necessária sua intervenção } \\
\text { Disponível em: https://do.corumba.ms.gov.br/corumba/portal/ommunitycões/ } \\
\text { pdf/3639/\#/p:1/e:3639 }\end{array}$ \\
\hline $20 / 4 / 2020$ & n. ${ }^{\circ} 2.289$ & $\begin{array}{l}\text { D E C R E T A: } \\
\text { Art. 1. }{ }^{\circ} \text { Ficam estabelecidas, neste decreto, as normas temporárias relacionadas às } \\
\text { reuniões religiosas em igrejas, templos, centros espíritas e demais locais destinados } \\
\text { a manifestações religiosas. } \\
\begin{array}{l}\text { Disponível em: https://do.corumba.ms.gov.br/corumba/portal/visualizacoes/ } \\
\text { pdf/3658/\#/p:1/e:3658 }\end{array}\end{array}$ \\
\hline $16 / 7 / 2020$ & n. ${ }^{\circ} 2.356$ & $\begin{array}{l}\text { Art. } 2 .^{\circ} \text { Os templos religiosos realizarão suas celebrações nos moldes estabelecidos } \\
\text { em regulamentos anteriores, zelando pelo cumprimento de normas de biossegurança } \\
\text { e deverão, de modo adicional, registrar, por meio próprio, o nome, idade e telefone } \\
\text { do fiel presente ao ato, caso haja a necessidade de realização de contatos posteriores, } \\
\text { mantidas as demais regras estabelecidas no Decreto n. }{ }^{\circ} 2289 / 2020 \\
\text { Disponível: } \\
\text { õttps://do.corumba.ms.gov.br/corumba/portal/ommunity }\end{array}$ \\
\hline $30 / 7 / 2020$ & n. ${ }^{\circ} 2.364$ & $\begin{array}{l}\text { D E C R E T A: } \\
\text { Art. } 1 .^{\circ} \text { Fica estabelecido o horário de funcionamento do comércio em geral e de } \\
\text { prestação de serviços, de segunda-feira a sexta-feira, das } 8 \mathrm{~h} \text { às } 16 \mathrm{~h} \text { e, aos sábados, } \\
\text { das } 8 \text { h às } 14 \mathrm{~h} \text {, vedado seu funcionamento aos domingos. }\end{array}$ \\
\hline $25 / 8 / 2020$ & n. ${ }^{\circ} 2.381$ & $\begin{array}{l}\text { Art. 3. Fica autorizado o funcionamento de igrejas, templos, centros espíritas e de- } \\
\text { mais locais destinados a manifestações religiosas, observadas as normas de biosse- } \\
\text { gurança já editadas, respeitadas as seguintes limitações: I - de segunda a sexta-feira: } \\
\text { um culto, missa ou outra demonstração religiosa por dia. II - sábados e domingos: } \\
\text { dois cultos, missas ou outra demonstração religiosa por dia. (NR) } \\
\text { Disponível em: https://do.corumba.ms.gov.br/corumba/portal/visualizacoes/ } \\
\text { pdf/3772/\#/p:1/e:3772 }\end{array}$ \\
\hline
\end{tabular}




\section{Figura 9}

Distribuição geográfica de templos e centros religiosos em Corumbá-MS

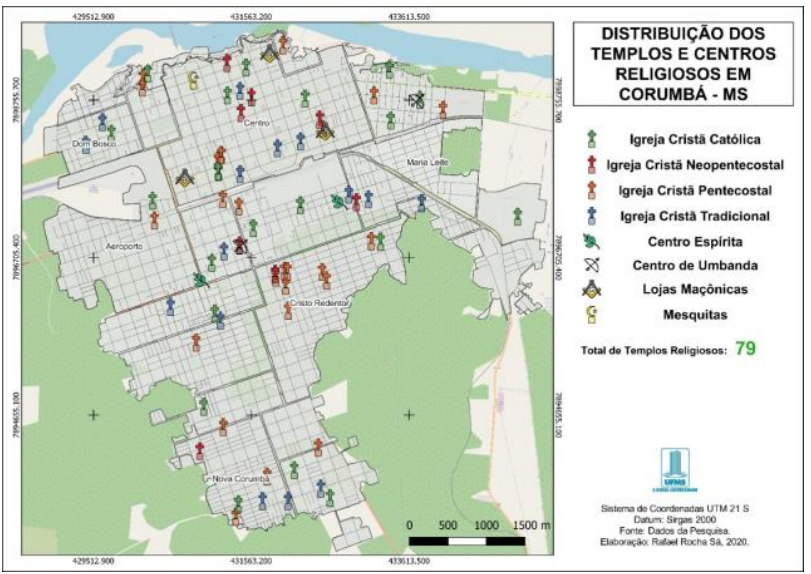

Autores a partir do IBGE Cidades-Corumbá, 2020.

Nesse sentido, buscamos correlacionar o quantitativo de templos religiosos existentes por bairro, conforme a Figura 9:

De acordo com o IBGE (2010), os bairros com maior índice populacional são Centro, Cristo Redentor, Nova Corumbá, Popular Velha e Aeroporto. E como pode ser observado em Figuras 7 e 8 , esses bairros concentram o maior número de casos de Covid-19, bem como o de maior número de óbitos.

\section{Considerações finais}

Diante dos dados aqui analisados pode-se inferir que a pandemia de Covid-19, por ser uma emergência de saúde pública internacional, deveria ter sido levada mais a sério pelo conjunto de gestores públicos, do prefeito ao presidente, assim como por diferentes setores da sociedade brasileira. Até a data de 28 de dezembro de 2020, o Brasil contabilizou 191 mil óbitos e mais de 7 milhões de contaminados. Acrescenta-se que a mesma limitação deveria ter sido mantida para bares e restaurantes, por exemplo, para evitar aglomerações. O saldo de casos e óbitos acumulados de Covid19, em Corumbá, até o dia 28 de dezembro de 2020, é de 6501 e 189 respectivamente. Como aponta os dados da Secretaria Estadual de Saúde de MS, a macrorregião de saúde de Corumbá responde por 10\% dos óbitos de MS, mas possui apenas 4

As medidas preventivas de isolamento tomadas no mês de março de 2020, com o intuito de reduzir a difusão do vírus pela cidade, foram eficazes para a população. Isso nos leva a concluir que aquelas medidas deveriam ter sido mantidas, uma vez que, quando houve a flexibilização para o funcionamento dos templos religiosos pelo Decreto Municipal n. ${ }^{\circ} 2.289$, de 20 de abril de 2020, verificou-se rápida disseminação do Sars-Cov-2, pois, como os estudos científicos sinalizaram, ambientes fechados com circulação de ar limitada propiciam a contaminação de pessoas por coronavírus, porque ele é capaz de sobreviver no ar. Logo, os cultos e as missas presenciais deveriam ter sido mantidos suspensos, assim como as aulas, até que se verificasse a queda nos números de contaminados e de óbitos.

Observou-se pelos dados epidemiológicos e de geolocalização, que onde existe uma maior concentração de templos religiosos, são os bairros com maiores números de casos confirmados de Covid-19 e com maior número de óbitos registrados, tais como os bairros da parte Central, Aeroporto, Cristo Redentor e Popular Nova.

Essa informação preocupante, deveria ser objeto de trabalho dos gestores, no sentido de orientar a população e os dirigentes dos templos religiosos, a não organizar reuniões com seus fiéis ou realizar atividades à distância, como recomendação de saúde, o que não ocorreu. O coronavírus é altamente contagioso, por isso, a necessidade de se manter o distanciamento físico, uso de máscara e o isolamento social para que o menor números pessoas possam ficar exposta a esse vírus que é bastante letal para as pessoas acimas de 60 anos e que apresentam doenças crônicas.

Portanto, isso nos faz reforçar a importância das medidas que já foram impostas antes com o isolamento, até que possa existir uma vacina contra o vírus. As medidas de prevenção e de controle da Covid-19 são necessárias para conter a doença, mas têm custos em diversas áreas, a curto e a longo prazos.

Então cabe às autoridades públicas tomarem medidas restritivas para não sobrecarregar o sistema de saúde que atende a população local, a cidade de Ladário e algumas cidades da fronteira. O distanciamento social e o isolamento são medidas essenciais para conterem o contágio e evitar novas mortes por Covid-19.

\section{Referências}

Agência Senado, Brasília (3 de julho de 2020). Bolsonaro veta uso obrigatório de máscara no comércio, em escolas e em igrejas. https://www12.senado.leg. br/noticias/materias/2020/07/03/bolsonaro-veta-usoobrigatorio-de-mascara-no-comercio-em-escolas-e- 
em-igrejas. Acesso em: 27 de julho de 2020.

Barbosa, C. (4 de agosto de 2020). Mais de 400 padres diocesanos já contraíram Covid-19 e 21 morreram, aponta relatório. https://www.brasildefato.com. br/2020/08/04/mais-de-400-padres-diocesanos-jacontrairam-covid-e-21-morreram-aponta-relatorio. Acesso em: 18 de setembro 2020. Brasil de Fato.

Brasil. (20 de março de 2020). Decreto Presidencial n. ${ }^{\circ}$ 10.282, de 20 de março 2020. regulamenta a Lei n. ${ }^{\circ} 13.979$, de 6 de fevereiro de 2020, para definir os serviços públicos e as atividades essenciais. https://www.in.gov.br/en/web/dou/-/ republicacao-249098206. Acesso em: 1. ${ }^{\circ}$ de julho de 2020. DiárioOficialdaRepúblicaFederativadoBrasil, Brasília.

Brasil. (20 março de 2020). Medida Provisória n. ${ }^{\circ}$ 926/2020. Altera a Lei n. ${ }^{\circ} 13.979$, de 6 de fevereiro de 2020, para dispor sobre procedimentos para aquisição de bens, serviços e insumos destinados ao enfrentamento da emergência de saúde pública de importância internacional decorrente do coronavírus. https://www.camara.leg.br/proposiç oesWeb/ fichadetramitacao?idProposicao $=2241660$. Acesso em: 17 de setembro de 2020. Câmara Legislativa Federal, Brasília.

Cazarré, M. (16 de março de 2020). Países fecham fronteiras para evitar propagação do coronavírus. https://agenciabrasil.ebc.com.br/geral/noticia/202003/paises-fecham-fronteiras-para-evitar-propagacaodo-coronavirus. Acesso em: 15 de setembro de 2020. Agência Brasil, Brasília.

Cerioni, C.; Garret Junior, G. (7 de julho de 2020). Casos da Covid-19 dobram em SC após reabertura de shoppings e igrejas. https://exame.com/brasil/casos-da-covid19-dobram-em-sc-após-reabertura-de-shoppings-eigrejas/. Revista Exame.

Corumbá. (21 de março de 2020). Decreto Municipal n. ${ }^{\circ} 2.268$, de 21 de março 2020. Reconhece situação de emergência no Município de Corumbá, em decorrência da pandemia do Coronavírus Covid-19. https://do.corumba.ms.gov.br/corumba/ portal/visualizacoes/pdf/3638/\#/p:1/e:3638. Acesso em: 18 de setembro de 2020. Diário Oficial, Corumbá-MS.

Corumbá. (23 de março de 2020). Decreto Municipal n. ${ }^{\circ}$ 2.270, de 23 de março de 2020. Institui Comitê Gestor de Crise - Pandemia Covid-19, e dá outras providências. https://do.corumba.ms.gov.br/corumba/portal/. Acesso em: 18 de setembro de 2020. Diário Oficial,
Corumbá-MS.

Corumbá. (20 de abril de 2020). Decreto Municipal n. ${ }^{\circ} 2.289$, de 20 de abril de 2020. Regulamenta o funcionamento de igrejas e templos de qualquer culto no âmbito do Município de Corumbá em decorrência da pandemia do Coronavírus Covid-19. https://do.corumba.ms.gov.br/corumba/ portal/visualizacoes/pdf/3658/\#/p:1/e:3658. Acesso em: 18 de setembro de 2020. Diário Oficial, Corumbá-MS.

Corumbá. (16 de julho de 2020) Decreto Municipal n. ${ }^{\circ}$ 2.356, de 16 de julho de 2020. Dispõe sobre a reavaliação e readequação de medidas de combate ao Covid19, e dá outras providências. https://do.corumba.ms. gov.br/corumba. Acesso em: 18 de setembro de 2020. Diário Oficial, Corumbá-MS.

Corumbá. (30 de julho de 2020). Decreto Municipal n. ${ }^{\circ}$ 2.364 de 30 de julho de 2020. Dispõe sobre o estabelecimento de medidas restritivas às atividades que especifica, como forma de frear a circulação do Coronavírus - Covid-19, e dá outras providências. https: //do.corumba.ms.gov.br/corumba. Acesso em: 18 de setembro de 2020. Diário Oficial, Corumbá-MS.

Corumbá. (25 de agosto de 2020). Decreto Municipal n. ${ }^{\circ}$ 2.381 de 25 de agosto de 2020. Altera o decreto n. ${ }^{\circ}$ 2.364 de 29 de julho de 2020, e dá outras providências. https://do.corumba.ms.gov.br/corumba/portal/ visualizacoes/pdf/3772/\#/p:1/e:3772. Acesso em: 18 de setembro de 2020. Diário Oficial, Corumbá-MS.

Corumbá. (17 de junho de 2020). Boletim Covid-19, 2020. Secretaria Municipal de Corumbá. https: //www.corumba.ms.gov.br/wp-content/uploads/2020/ 05/Boletim-dia-17-06.pdf.

Delatorre, E.; Mir, D.; Gräf, T.; Bello, G. (16 de setembro de 2020) Tracking the onset date of the community spread of SARS-CoV-2 in Western Countries. https://memorias.ioc.fiocruz.br/article/10702/0183tracking-the-onset-date-of-the-community-spreadof-sars-cov-2-in-western-countries. Memórias Instituto Oswaldo Cruz, Rio de Janeiro.

De Lima Bezerra, V. et al. (2020, v. 3, n. 4, p. 8.4528.467). SARS-CoV-2 como agente causador da Covid-19: epidemiologia, características genéticas, manifestações clínicas, diagnóstico e possíveis tratamentos. Brazilian Journal of Health Review.

Estado de Minas (16 de março de 2020). Coreia do Sul tem novo foco de coronavírus vinculado a uma igreja. https:/www.em.com.br/app/noticia/internacional/ 2020/03/16/interna_internacional,1129193/coreia- 
do-sul-tem-novo-foco-de-coronavirus-vinculado-auma-igreja.shtml. Acesso em: 1. ${ }^{\circ}$ de julho de 2020. Estado de Minas, Belo Horizonte.

Estellita, M. C. A. et al. (2020, v. 3, n. 3, p. 7.058-7.072). Análise do coronavírus SARS- CoV-2/Covid-19 no cenário atual da pandemia mundial: revisão de literatura/Analysis of the coronavirus SARS-CoV-2/Covid19 in the current world pandemic scenario: literature review. Brazilian Journal of Health Review.

Fernandes, M. (1. ${ }^{\circ}$ de julho de 2020). Covid-19: culto em igreja nos EUA deixa $38 \%$ dos fiéis contaminados. https://www.correiobraziliense.com.br/app/noticia/ ciencia-e-saude/2020/05/19/interna_ciencia_saude, 856513/covid-19-culto-em-igreja-nos-eua-deixa-38dos-fieis-contaminados.shtml. Correio Braziliense, Brasília.

Fongaro, G. et al. (16 de setembro de 2020). SARS-CoV-2 in human sewage in Santa Catarina, Brazil, November 2019. https://www.medrxiv.org/content/10.1101/ 2020.06.26.20140731v1. MedRxiv.

Garcia, L. P. (19 de setembro de 2020). Uso de máscara facial para limitar a transmissão da Covid19. https:/www.scielosp.org/article/ress/2020.v29n2/ e2020023/pt/. Epidemiologia e Serviços de Saúde.

Gil, A. C. (2002). Como elaborar projetos de pesquisa. São Paulo: Editora 04; Atlas.

IBGE 2010. (5 de junho de 2020). Censo Cidades 2010. https://cidades.ibge.gov.br/brasil/ms/corumba/ pesquisa/23/22107.

IG Último Segundo. (6 de junho de 2020). Covid19: após reabertura de igrejas, EUA vê "explosão" de casos entre fiéis. https://ultimosegundo.ig.com. br/mundo/2020-06-17/covid-19-apos-reabertura-deigrejas-eua-ve-explosao-de-casos-entre-fieis.html. Acesso em: $1 .^{\circ}$ de julho 2020. IG Último Segundo.

Johns Hopkins University. (16 de setembro de 2020). Coronavirus Covid-19 Global Cases by Johns Hopkins CSSE. https://gisanddata. maps.arcgis.com/apps/opsdashboard/index.html\# /bda7594740fd40299423467b48e9ecf6.

Lana, R. M. et al. (2020). Emergência do novo coronavírus (SARS-CoV-2) e o papel de uma vigilância nacional em saúde oportuna e efetiva. Cadernos de Saúde Pública.

Lednicky, J. A. et al. (16 de setembro de 2020). Viable SARS-CoV-2 in the air of a hospital room with Covid-19 patients. https:/www.medrxiv.org/content/ 10.1101/2020.08.03.20167395v1.full.pdf+html. MedRxiv, Flórida.
Lopes, P. (20 de março de 2020). Em duas estratégias, um êxito e uma ópera trágica. https://piaui.folha.uol. com.br/em-duas-estrategias-um-exito-e-uma-operatragica/. Acesso em: 15 de setembro de 2020. PiauíFolha de São Paulo, São Paulo.

Nascimento, F. L. (2020, v. 2, n. 4, p. 1-9). Cemitério X novo coronavírus: Impactos da Covid-19 na Saúde Pública e Coletiva dos mortos e dos vivos. Boletim de Conjuntura (BOCA).

Oliveira, M. D. (jan./abr. 2020, v. 25, n. 1, p. 257-276). Cuidado pastoral da Igreja em tempos de pandemia: Covid-19. Revista Caminhando.

Oliveira, W. K. et al. (2020, v. 29, p. e2020044). Como o Brasil pode deter a Covid-19. Epidemiologia e Serviços de Saúde.

Pereira, L. S.; Sá, R. R.; Freitas, E. P. (maio de 2020, v. 5, n. 9, p. 100-105). A evolução da Covid-19: O caso de Corumbá-MS. Revista Ensaios de Geografia, Niterói.

Saquet, M. A. (set-dez, 2018, v. 20, n. 3, p. 479-505). A descoberta do território e outras premissas do desenvolvimento territorial. Revista Brasileira de Estudos Urbanos e Regionais, São Paulo.

Silva, E. F., da Silveira, E. S. (2020, v. 29, n. 3, p. 23426). A Pandemia de Covid-19 sob a benção de Bolsonaro e Evangélicos. Revista Inter-Legere.

Silva, R. S. M. et al. (2020, v. 31, n. supl. 1, p. 162183). Uso de máscaras de tecido pela população na contenção da disseminação da Covid-19: scoping review. Comunicação em Ciências da Saúde.

Souza, M. V. M.; Ferreira Júnior, D. B. (abril de 2020, n. 18). Rede urbana, interações espaciais e a geografia da saúde: análise da trajetória da Covid19 no estado do Pará. http://journals.openedition. org/espacoeconomia/13146; DOI: https://doi.org/10. 4000/espacoeconomia.13146. Acesso em: 21 de abril de 2020. Espaço e Economia [online].

Strapazzon, C. L. (2020, v. 21, n. 1, p. 297-306). Saúde e liberdade religiosa: o caso da Igreja Pentecostal South Bay United, julgado pela Suprema Corte dos Estados Unidos, no contexto da COVID-19. Espaço Jurídico Journal of Law [EJJL].

Triviños, A. N. S. (1987, 1. a ed.). Introdução à pesquisa em ciências sociais: a pesquisa qualitativa em educação. Atlas: São Paulo.

Tzanno-Martins, C. (19 de setembro de 2020, n. AHEAD). Pandemia Covid-19: das máscaras de carnaval às máscaras cirúrgicas. https://www.scielo.br/scielo.php? pid=S010128002020005029201\&script=sci_arttext\& tlng=pt. Brazilian Journal of Nephrology. 